\title{
AANWINST \\ EEN GROTE SCHOTEL MET BLOEMTAKKEN
}

Het Rijksmuseum heeft een grote schotel verworven van zogenoemd Kantonemail (afb. 1). De schotel is gemaakt van koper waarop allereerst aan beide zijden een dekkende witte laag email is vastgebakken. Vervolgens is in emailkleuren een voorstelling geschilderd van bloemtakken, waarbij vooral de pioenrozen, magnoliatakken, irissen en knobbelige vruchten, waarschijnlijk dwergkweeën, opvallen. Tussen de bloemen dartelen twee vlinders. $\mathrm{Na}$ het schilderen is het stuk opnieuw gebakken om de kleuren te laten hechten. Het Rijksmuseum bezat al een groep Kanton-email voorwerpen, maar een stuk van deze allure en kwaliteit ontbrak en daarom kan vanaf nu in de collectie voor het eerst recht worden gedaan aan de vaardigheden van de Chinezen die deze techniek in de $18^{\mathrm{e}}$ eeuw beoefenden.

Voorwerpen beschilderd in niet doorschijnende emailkleuren raakten aan het Chinese hof al voor 1700 in de mode. ${ }^{1}$ Deze techniek was in China niet bekend, maar als diplomatieke geschenken waren deze Europese producten in Peking terecht gekomen en zij hadden in hoge mate de belangstelling van keizer Kangxi gewekt. In 1687 schreef een van de missionarissen in Peking, Jean de Fontaney, dat voorwerpen beschilderd met emails uitstekend geschikt waren als geschenk. De keizer wilde in China zelf dergelijke voorwerpen laten maken en daarvoor was het noodzakelijk een aantal nieuwe kleuren te ontwikkelen, waarvan roze het meest in het oog springt. Bij de meeste kleuren op keramiek is een metaaloxide de kleurstof. Het roze wordt verkregen door opaak wit te mengen met rood en voor deze bijzondere rode kleurstof is goud de grondstof. In de keizerlijke werkplaatsen in Peking werd geprobeerd de benodigde technische kennis en vaardigheden te ontwikkelen en de aanwezigheid van de andere keizerlijke werkplaatsen in de onmiddellijke nabijheid vereenvoudigden dit proces. Chinese emailschilders werden uit het pottenbakkerscentrum Jingdezhen gehaald. Daar bestond immers al een eeuwenoude traditie in het schilderen met - weliswaar doorschijnende emails. In Peking konden zij profiteren van de kennis van vakgenoten uit de glas- en cloisonnéwerkplaats, want in alle drie de gevallen werd gewerkt met minerale kleurstoffen die in de vorm van een gesmolten glassubstantie toegepast werden. Uit technisch onderzoek blijkt dat de samenstelling van de meeste kleuren in Chinese geschilderde emails sterk overeenkomen met de emails die al eerder in de cloisonnétechniek werden toegepast. De verwerking van het rood dat noodzakelijk is voor het kenmerkende roze kan men geleerd hebben van Europese missionarissen in Peking. Goud werd al met succes als grondstof voor een rode kleur toepast bij de productie van glas in het Midden-Oosten en het recept was in de $17^{\mathrm{e}}$ eeuw in Venetië bekend. Het is goed mogelijk dat deze kennis vanuit de keizerlijke glaswerkplaats, waar sinds 1695 kundige Jezuieten-glasblazers aan het werk waren woor de $02: 43: 52 \mathrm{PM}$ emailschilders beschikbaar kwam. Volgens een andere theorie zou de kenniscess 
van het schilderen met opake emails in China eerst in Kanton tot ontwikkeling zijn gekomen door de samenwerking van plaatselijke emailwerkers en Franse missionarissen. In een oude Franse publicatie wordt zelfs 1683 als vroegste datum van deze kunstvorm genoemd, helaas zonder de verwijzing naar de bronnen waaruit dit blijkt. Maar in recente studies wordt de mogelijkheid dat de technische kennis in Kanton ontstond en vandaar Peking bereikte, nadrukkelijk opengelaten. ${ }^{2}$

Geen enkele kunstuiting kon zozeer op keizerlijke aandacht rekenen als het schilderen in emails. Keizer Kangxi zag er persoonlijk op toe dat missionarissen met kennis van zaken zich met de productie gingen bezighouden en hij droeg gouverneurs van Chinese provincies op om deskundigen naar Peking te sturen - zowel Europese missionarissen als Chinese handwerkslieden. In een brief uit 1720 vermeldde een van de missionarissen, Joseph de Mailla, dat de Chinezen op dat moment vijf à zes jaar met deze techniek bezig waren.

Afbeelding 2 Blad met het wapen van de familie Clifford, emails op koper, $37,7 \times 26,9 \mathrm{~cm}$., Kanton, ca. 1750, Rijksmuseum Amsterdam, AK-RBK1960-142. De familie Clifford kreeg in 1749 toestemming dit wapen te voeren.
In 1716 waren twee emailwerkers door de gouverneur van Kanton naar het hof gestuurd, met medeneming van de voorwerpen waarop zij in roze emails hadden geschilderd - gezien de datum inderdaad een aanwijzing voor de vroege ontwikkeling van de techniek in het zuiden van China. Drie jaar later arriveerde op verzoek van de missionarissen in Peking en na aandringen van keizer Kangxi een deskundige uit Frankrijk, Jean Baptiste Gravereau. Het blijft onduidelijk op welk moment de Chinezen de techniek tot ieders tevredenheid meester waren, vanaf welk moment ze zelf voor de grondstoffen konden zorgen en welk deel van het procédé nu door de Chinezen zelf ontwikkeld is.

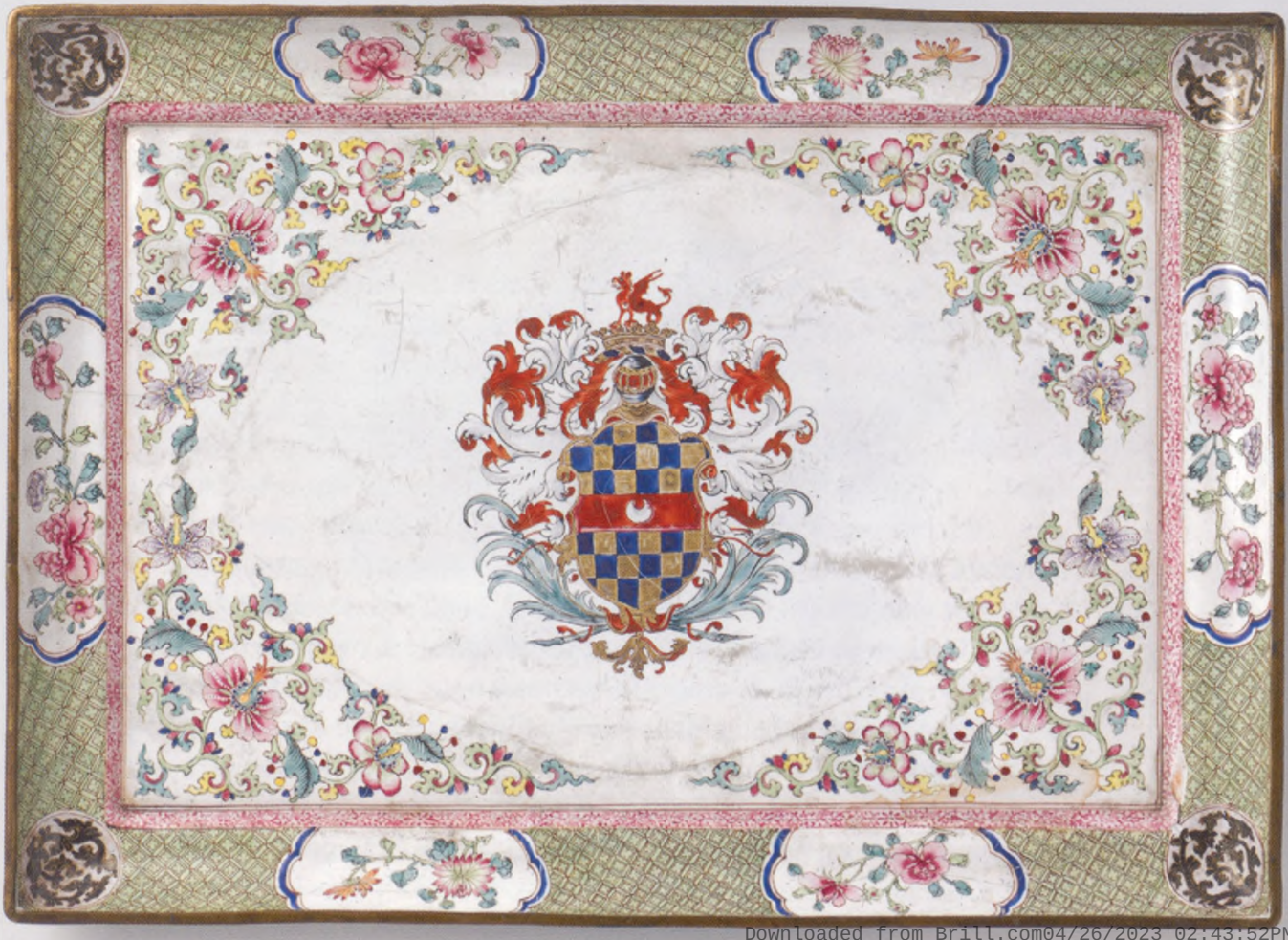



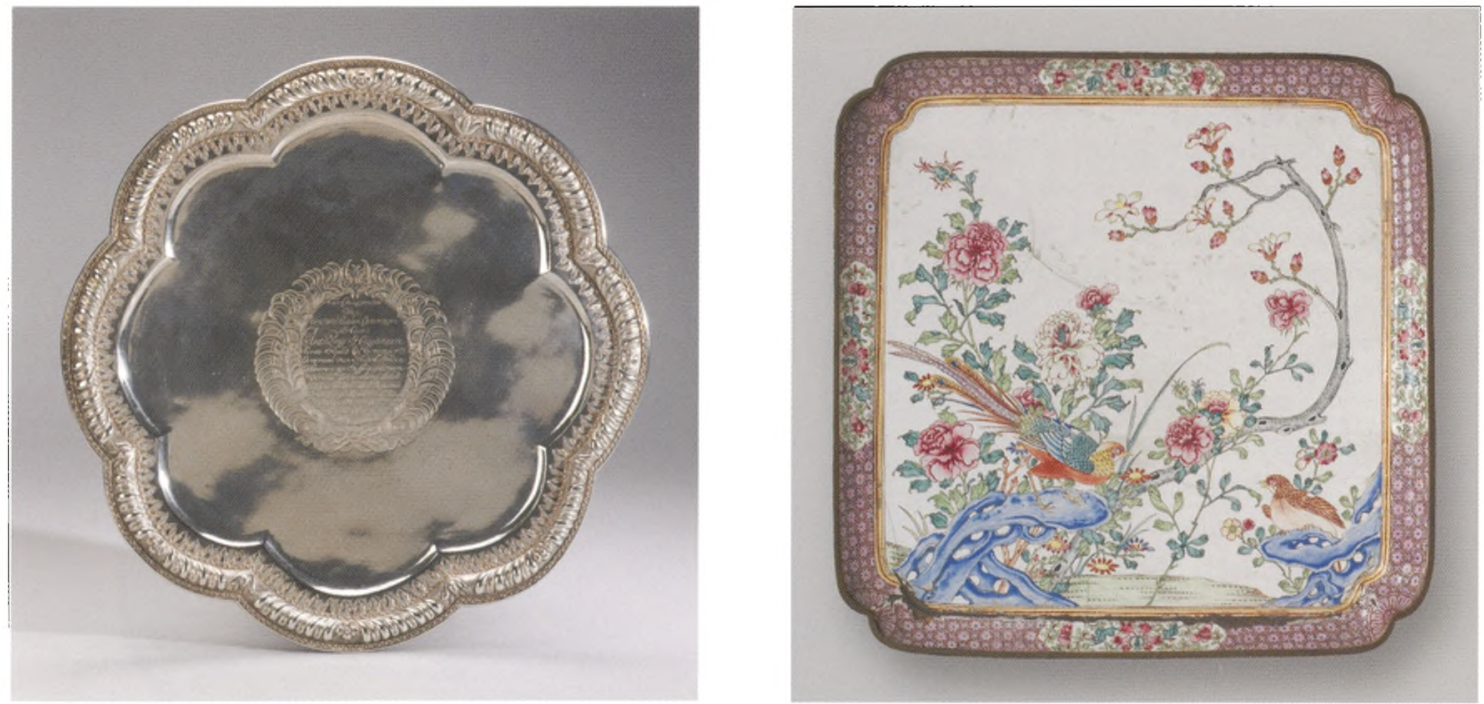

Afbeelding 3 Jan van Cloon, bord, zilver, d. $34,5 \mathrm{~cm}$., Batavia, 1729, Rijksmuseum Amsterdam BK-1994-79

Afbeelding 4 Blad, emails op koper, $28 \times 28 \mathrm{~cm}$., Kanton, 1730-1750, Rijksmuseum Amsterdam, AK-RBK-14815
Volgens het standaardwerk van Kerr en Wood was de ontwikkeling te danken aan 'considerable interaction between European specialists and Chinese craftsmen' en was toepassing van de techniek niet mogelijk geweest als er niet een sterke basis aan technische kennis in China zelf aanwezig was geweest. In de Yongzheng-periode (1723-1735) werden de laatste problemen opgelost en het begin van de Qianlong-periode (vanaf 1736) geldt als een bloeiperiode voor de emailschilderkunst. Evenals Kangxi hadden zijn opvolgers grote belangstelling voor deze kunstvorm. Met emails werd geschilderd op koper, goud, zilver, glas en porselein. Uit Jingdezhen werden speciaal geselecteerde stukken porselein naar Peking gestuurd om daar met emails beschilderd te worden.

Naast de exquise productie in Peking werd zowel in Jingdezhen als in Kanton al snel op veel grotere schaal geschilderd met de emailkleuren, een productie die deels voor de export bestemd was. Er is een verschil tussen de licht verstikkende precisie van de stukken voor het hof en de duidelijk met een grotere vaart geschilderde stukken voor de markt. Er werd vooral op porselein geschilderd, maar omdat de techniek en decors op koper en porselein zo verwant zijn, gaat men ervan uit dat in Kanton in dezelfde ateliers zowel op koper als op porselein werd gewerkt. De nieuwverworven schotel van het Rijksmuseum is waarschijnlijk uit zo'n Kantonese werkplaats afkomstig, uit de periode dat de technische problemen zojuist waren overwonnen - omstreeks 1730. Voordeel voor de ateliers in Kanton was dat zij gemakkelijker konden inspelen op de specifieke wensen van de Europese kopers. Zo zijn in Kantonemail voorwerpen bekend met familiewapens waarvoor deze kwestie bij uitstek opportuun was. Een voorbeeld hiervan is een blad uit de Rijksmuseumcollectie met het wapen van de familie Clifford (afb. 2).

In het geval van de nieuwe aanwinst valt van de decoratie niet te zeggen of deze speciaal naar wens van een Europese koper is aangebracht. De vorm is wel eerder Europees dan Chinees. De achtlobbige rand is verwant aan zilveren schotels die ondermeer bekend zijn uit Batavia en ongeveer uit dezelfde tijd stammen. In de Rijksmuseumcollectie bevinden zich twee 02:43:52pM exemplaren, één uit 1729 en één uit 1730 (afb. 3). ${ }^{3}$ Daarnaast bevindt zich in 
Afbeelding 5 Schotel, emails op koper, d. 46,5 cm., Kanton, 1730-1750, uit: Roger Keverne, Winter Exhibition 2000

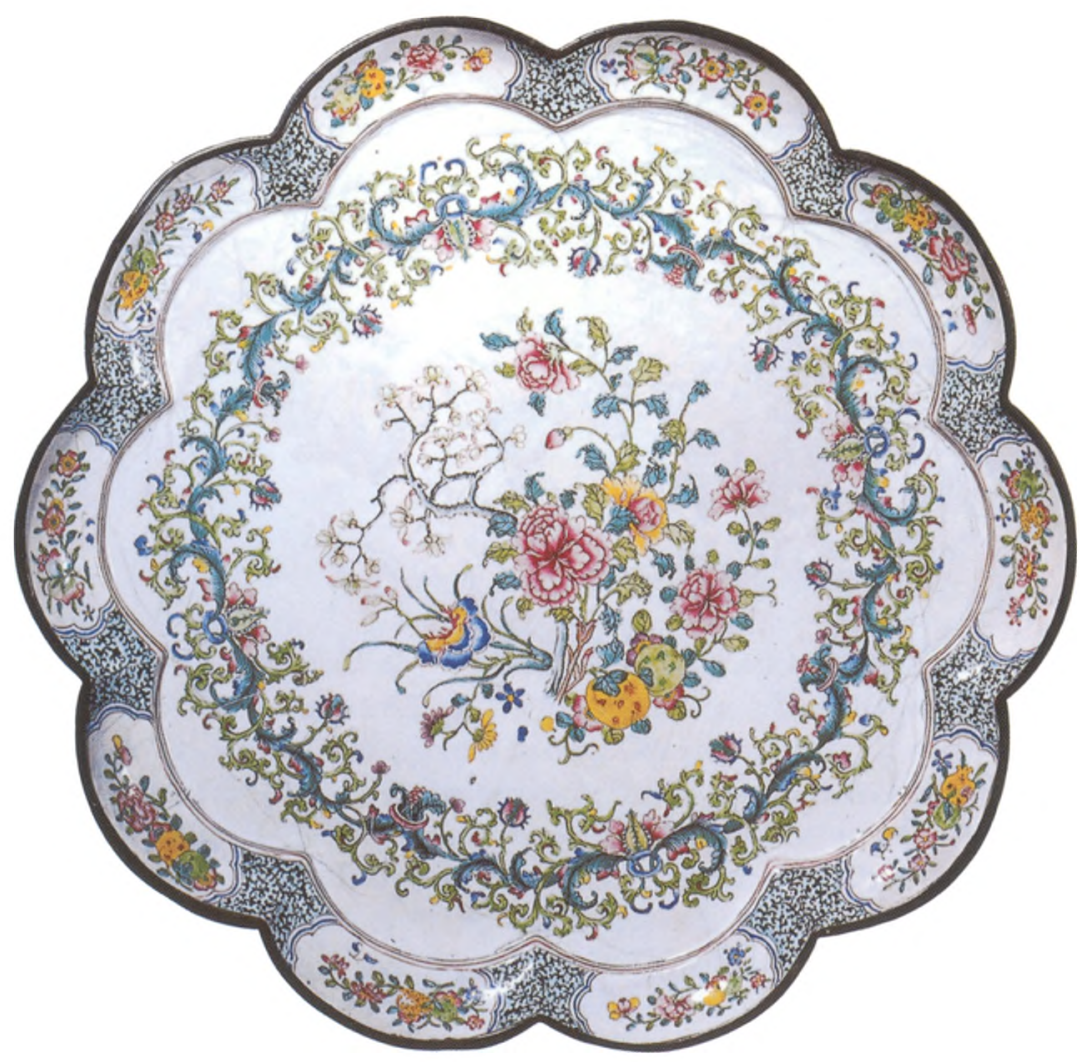

de collectie een zeslobbige schotel van koper, waarschijnlijk uit het tweede kwart van de $18^{\mathrm{e}}$ eeuw. ${ }^{4}$ Gezien het royale formaat en de volledig vlakke bodem kan de schotel een functie als theeblad hebben gehad. Thee was in de $18^{\mathrm{e}}$ eeuw bijzonder geliefd geworden en aan theegerei (potten, koppen, schotels, theekistjes, etc.) werd veel aandacht besteed en geld uitgegeven. De slijtsporen op het blad tonen aan dat er harde voorwerpen, waarschijnlijk theegoed, op gestaan hebben en overheen geschoven zijn. Het blad heeft dus zeker niet uitsluitend als sierstuk gediend. In inventarissen en ladinglijsten worden grote hoeveelheden theebladen van Chinees lakwerk genoemd (waarvan er betrekkelijk weinig over zijn). Ook van Kanton-email zijn theebladen bekend. Het Rijksmuseum bezit naast het al genoemde blad met het wapen van Clifford een kleiner vierkant blad met een voorstelling van fazanten op een rots bij bloeiende planten ( $\mathrm{afb}$. 4). In enkele openbare collecties bevinden zich grote bladen: een voorbeeld van een groot rechthoekig exemplaar bevindt zich in het Museum voor Oost-Aziatische Kunst in Stockholm, een rechthoekig blad met een gelobde rand in het National Museum of Scotland, Edinburgh. ${ }^{5}$ In beide gevallen zijn de stukken beschilderd met fazanten en bloeiende planten, net als op het kleine blad uit het Rijksmuseum. Door de spanningen bij het bakken, zeker bij grote min of meer vlakke voorwerpen, is de kans groot op barsten en het afspringen van stukken email. Dat grote stukken toch met enige regelmaat met succes werden vervaardigd, toont het meesterschap van de emailwerkers. Deze specifieke vorm met een achtlobbige rand, is tot op heden in Kanton-email 43 :52PM slechts van één andere schotel van groot formaat bekend (afb. 5). ${ }^{6}$ via free access 
Opvallend aan de nieuwe Rijksmuseum-schotel is de grote vrijheid waarmee de bloemtakken in het vlak zijn geplaatst en zijn geschilderd. Dat de eisen voor de stukken bestemd voor het hof tot stijfheid leidden, is opgemerkt; dat het eindeloos in serie vervaardigen van steeds dezelfde decors tot ongeïnspireerdheid leidt, valt te begrijpen. Dit valt ook bij de twee andere afgebeelde blaadjes uit de Rijksmuseumcollectie te herkennen. Tegen die achtergrond is de vrijheid in de compositie en het penseelwerk in de nieuwe schotel opvallend. De bloemtakken vormen vloeiende lijnen en de schilder lijkt van een strikte behoefte aan logica te hebben afgezien. Deels lijken de bloemen opgevat als een boeket waarbij de stelen linksonder zijn samengenomen, maar deels ook zijn de bloemen uitgestrooid. De dichtheid van de decoratie is niet gelijk verdeeld over het vlak, zonder dat het geheel onevenwichtig aandoet. De lambrequins zorgen voor een grillige maar toch regelmatige omlijsting waarin de bloemdecoratie het best tot zijn recht komt. Het decor van uigestrooide bloemtakken (juist ook in combinatie met een onregelmatige ornamentele band) komt regelmatig voor op kleine schoteltjes, maar op dit monumentale formaat is het effect natuurlijk veel indrukwekkender. ${ }^{7}$ Het schilderwerk is zeer geslaagd. De kleuren in de bloemen vervloeien prachtig. Maar de kwaliteit van de schilder komt ook tot uiting in de brokaatrand met bloemvelden. De precisie waarmee het motief voortgaat, zorgt ervoor dat de rand een vol geschilderde, maar toch rustige omlijsting van het geheel vormt. Hetzelfde kan opgemerkt worden over de blauwe motieven in de lambrequins.

Een zo vrije manier van schilderen is zowel voor een productie voor het hof als voor de export zeldzaam. De artisticiteit van de schotel doet haast vermoeden dat een emailschilder buiten het knellende productiepatroon van arbeidsdeling en tijdsdruk waarin hij werkte, op een avond in één keer een fraai geheel heeft willen maken. Of dat een 'echte' schilder voor één keer in een emailwerkers-atelier op email heeft gewerkt. Dat zijn natuurlijk romantische mijmeringen - het is gewoon een gelukkige toevalstreffer.

\section{Noten}

1. De meest definitieve tekst over geschilderde emails is te vinden in R. Kerr en N. Wood, Ceramic Technology (Vol. 5, part XII van Joseph Needham's Science and Civilisation in China), Cambridge, 2004, pp. 634-651.

2. Zie hiervoor de inleiding van Michael Gillingham in de catalogus van de Chinese Porcelain Company, Chinese Painted Enamels of the 18th Century, New York, 1993 en Kerr en Wood, Op.cit. (noot 1), p. 639.

3. BK-1994-79 en BK-1994-80.

4. BK-NM-2424.

5. J. Wirgin, Fran Kina till Europa, Stockholm, 1998, nr. 261; vriendelijke mededeling Inbal Livne, assistent curator, gepubliceerd in International exhibition of Chinese art, Londen, 1935, nr. 2202.

6. Voor een kleiner exemplaar met een geschulpte rand, zie M. Gillingsham, Chinese painted enamels (tent.cat. Ashmolean Museum, Oxford), Oxford, 1978, nr. 106.

7. Kleine schotels met een vergelijkbaar decor: J.A. Lloyd Hyde, Chinese painted enamels from private and museum collections (tent.cat. China House Gallery, New York), New York, 1969, nr. 48; Gillingham, Op.cit. (noot 4), nr. 74 en verder met enige regelmaat in veilings- en handelarencatalogi, bijvoorbeeld in Chinese painted Enamels, Op.cit. (noot 2), nr. 27. 


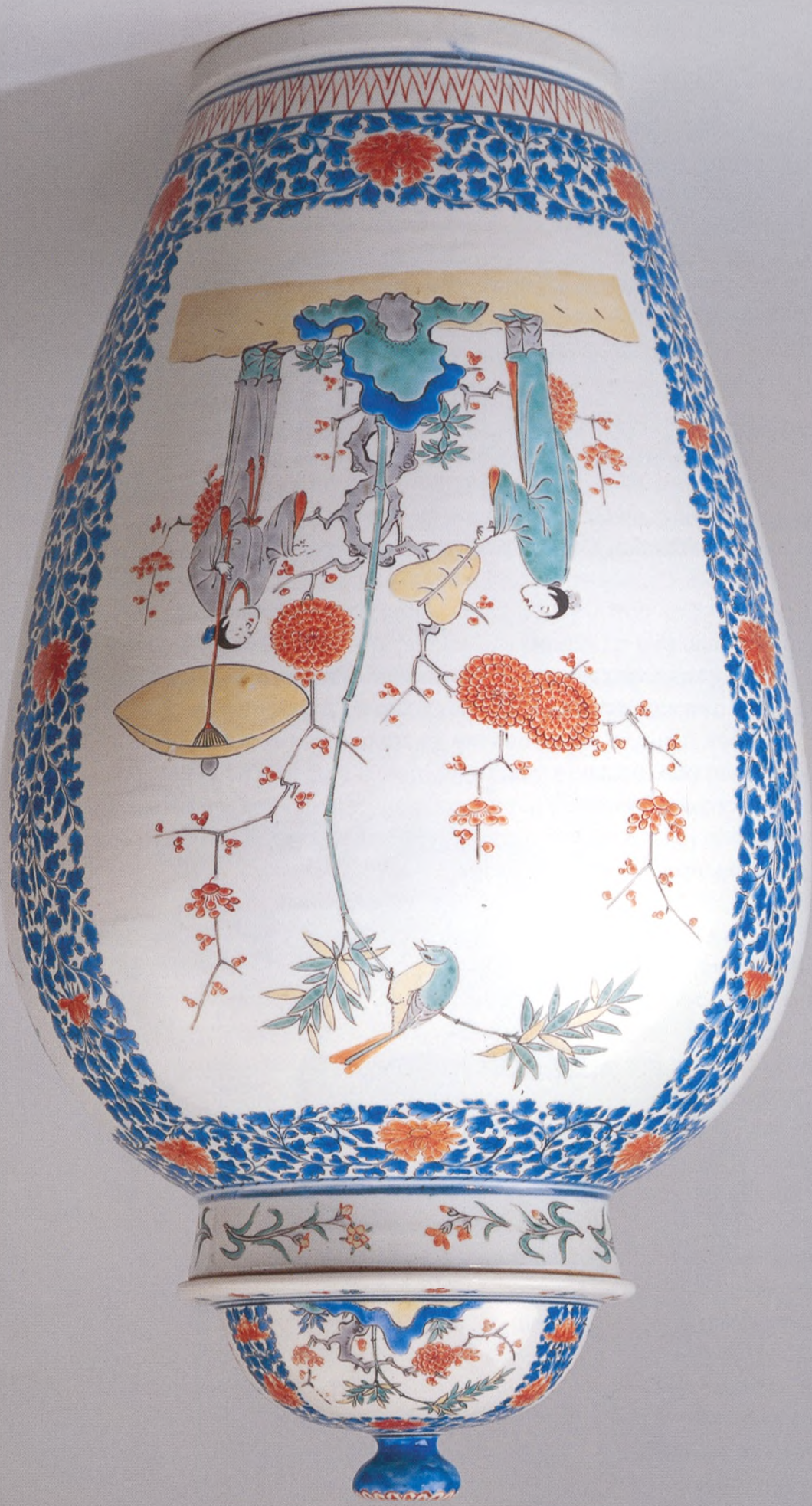

